\title{
Sun protection factor, total phenol, flavonoid contents and antioxidant activity of medicinal plants from Iran
}

\author{
Zahra Hashemi ${ }^{1}$, Mohammad Ali Ebrahimzadeh ${ }^{1 \star}$, Masoumeh Khalili ${ }^{2}$ \\ ${ }^{1}$ Pharmaceutical Sciences Research Center, Hemoglobinopathy Institute, School of Pharmacy, and Student Research \\ Committee, Mazandaran University of Medical Sciences, Sari, ${ }^{2}$ Neuroscience Research Center, Golestan University of Medical \\ Sciences, Gorgan, Iran
}

*For correspondence: Email: zadeh20@yahoo.com; Tel: +98-11-33543081-3; Fax: +98-11-33543084

Sent for review:

Revised accepted: 3 November 2018

\begin{abstract}
Purpose: To evaluate the correlation between sun protection factor (SPF) and the content of phenol and flavonoid and antioxidant activity.

Methods: Different parts of 9 medicinal plants were extracted with methanol using three extraction methods (percolation, Soxhlet and ultrasonically assisted extraction) to obtain 42 crude extracts. Their phenol and flavonoid contents, and antioxidant activities were determined using Folin-Ciocalteu reagent, aluminum chloride method and DPPH radical-scavenging activity, respectively. The SPF values were determined and correlated with the phenol and flavonoid contents as well as antioxidant activities.

Results: The phenol and flavonoid contents, and antioxidant activities ranged from 54.16-688.97mg GAE/g, 13.38-146.60 mg QE/g and 9.5-1472.4 $\mu \mathrm{g} / \mathrm{mL}$, respectively while the SPFs were between 0.067 and 0.841. The highest SPF was related to Cucumis melo L. ultrasonically assisted leaf extract (0.841) and Artemisia absinthium L., aerial parts extracted with percolation method (0.717). A significant correlation was found between SPF and phenolic $(p=0.003)$ and flavonoid contents $(p=0.023)$.

Conclusion: This study showed a correlation between SPF and phenolic and flavonoid contents. Ultrasonically assisted extract of C. melo leaf has suitable SPF and can be used in sun screen formulations.
\end{abstract}

Keywords: Artemisia absinthium, Cucumis melo, Echium amoenum, Orobanche orientalis, Sambucus ebulus, Sun burn, Sun protection factor, flavonoids, phenols

\begin{abstract}
This is an Open Access article that uses a fund-ing model which does not charge readers or their institutions for access and distributed under the terms of the Creative Commons Attribution License (http://creativecommons.org/licenses/by/4.0) and the Budapest Open Access Initiative (http://www.budapestopenaccessinitiative.org/read), which permit unrestricted use, distribution, and reproduction in any medium, provided the original work is properly credited.

Tropical Journal of Pharmaceutical Research is indexed by Science Citation Index (SciSearch), Scopus, International Pharmaceutical Abstract, Chemical Abstracts, Embase, Index Copernicus, EBSCO, African Index Medicus, JournalSeek, Journal Citation Reports/Science Edition, Directory of Open Access Journals (DOAJ), African Journal Online, Bioline International, Open-J-Gate and Pharmacy Abstracts
\end{abstract}

\section{INTRODUCTION}

About one million people are diagnosed with skin cancer every year [1]. Exposure to solar radiation has negative effects on the skin [2]. Ultraviolet light is mainly responsible for skin damage [1]. Sunscreens absorb or block UV rays of sunlight. There is some information regarding possible adverse reaction by synthetic sun-screen products [3]. There is little published data describing the use of herbal sunscreens and their sun protection factor (SPF) [4].

Natural substances have been recently considered as potential sources for agents with sunscreen properties [5] because of their absorption in the UV region [6] and their antioxidant activity [7]. Green tea polyphenols, 
aromatic compounds from lichens, glycosides of aesculin and Murraya koenigii are examples of natural substances evaluated for their sunscreen properties [8-10]. UV radiation increases oxidative stress in skin cells leading to cancer initiation and promotion. There has been an increasing interest in the use of antioxidants in sunscreens to provide supplemental photo protective action. Antioxidants from natural sources may provide new possibilities for the treatment and prevention of UV mediated diseases [7].

The Iranian flora is rich in medicinal plants with a high potential for providing these antioxidants. Among them, Sambucus ebulus, Artemisia absinthium and Cucumis melo are three medicinal plants with high antioxidant activities [11-13]. There are very limited reports on correlation between phenol/flavonoid contents or antioxidant activity and their SPF values [14].

The goals of this research were to evaluate: 1 ) SPF of 42 extracts from nine medicinal plants; 2) the phenol and flavonoid contents of the plants; 3 ) the antioxidant activities of the plants and 4) the correlation between SPF and the content of phenol and flavonoid and antioxidant activity.

\section{EXPERIMENTAL}

\section{Plant material and preparation of freeze-dried extract}

Cucumis melo L. (Cucurbitaceae), aerial parts, leaf and fruit, Sambucus nigra L. (Caprifoliaceous), leaf, fruit and bark, Artemisia absinthium L. (Asteraceae), and Orobanche orientalis G. Beck (Orobanchaceae), aerial parts, Vicia faba L. (Fabaceae), bean and hall, Albizzia julibrissin Durazz. (Fabaceae/Leguminosae), leaf and flower, Danae racemosa Moench. (Liliacae), leaf, Sambucus ebulus L. (Caprifoliaceous), flower and Echium amoenum Fisch and CA Mey. (Boraginaceae), petals were obtained in spring and summer, from Sari, Iran. Samples were authenticated by Dr Bahman Eslami and their voucher specimens were deposited (no. 10171025) in Sari School of Pharmacy herbarium. The plant materials were allowed to dry at room temperature for 2 weeks, and milled to obtain 2-3 $\mathrm{mm}$ particles for incubation with methanol to obtain methanolic extracts. Extracts were separated from the sample residues by filtration using filter paper and the process was repeated three times. The resulting extracts were concentrated using a rotary evaporator under vacuum at $36 \pm 2{ }^{\circ} \mathrm{C}$ and the crude solid extracts were freeze-dried for complete solvent removal.

\section{Ultrasonically-assisted extraction}

Samples were extracted with methanol in an ultrasonic bath by indirect sonication (frequency of $60 \mathrm{kHz}$ ) at $25 \pm 2{ }^{\circ} \mathrm{C}$ for $1 \mathrm{~h}$. The extracts were then separated from the samples residue by filtration. Resultant extracts were concentrated in a rotary evaporator until a crude solid extracts were obtained, which then freeze-dried for complete solvent removal [15].

\section{Soxhlet-assisted extraction}

Powdered samples were incubated with methanol for $24 \mathrm{~h}$ in a Soxhlet extractor. The extracts were concentrated in a rotary evaporator to completely remove the solvent.

\section{Determination of total phenolic and flavonoid contents}

Total phenolic content was measured colorimetrically using Folin-Ciocalteu reagent [15]. The results were expressed as gallic acid equivalents (GAE). Total flavonoids were estimated using $\mathrm{AlCl}_{3}$ method [16] and the contents calculated based on quercetin as standard from a calibration curve.

\section{Evaluation of DPPH radical-scavenging activity}

1,1-Diphenyl-2-picryl hydrazyl radical (DPPH) was used to assay free radical-scavenging activity of the extracts [17]. To $1 \mathrm{ml}$ of each extract (different concentrations, ranging from $25-800 \mu \mathrm{g} / \mathrm{mL}$ ) $1 \mathrm{ml}$ methanol solution of DPPH $(100 \mu \mathrm{M})$ was added. After 15 min incubation at room temperature in the dark, the absorbance was recorded at $517 \mathrm{~nm}$. The experiment was done in triplicates using vitamin $\mathrm{C}$ and butylated hydroxyl anisole (BHA) as positive controls.

\section{Computation of in vitro SPF}

The extracts were dissolved in methanol and scanned in the range of 337.5 to $292.5 \mathrm{~nm}$ (at five $\mathrm{nm}$ intervals) as previously described [18]. Screening of sun protection activity was then measured by determination of in vitro SPF based on the following equation proposed by Gharavi et al [19]:

$S P F=\frac{\sum_{292.5}^{37.5} \mathrm{E}(\lambda) \varepsilon(\lambda)}{\sum_{292.5}^{37.5} \mathrm{E}(\lambda) \varepsilon(\lambda) \mathrm{T}(\lambda)}$

where $T(\lambda)$ is the measured sun screen transmittance at $\lambda ; E(\lambda)$ is the spectral irradiance of terrestrial sunlight at $\lambda$; and $\varepsilon(\lambda)$ is the erythemal action spectrum at $\lambda$. The $E(\lambda)$ and $\varepsilon(\lambda)$ 
values were calculated as described previously [19]. For each extract, $T(\lambda)$ was measured three times and the means was used for SPF calculation. At least five different concentrations of each extract were used to obtain the standard curve and in calculating SPF in $2 \mathrm{mg} / \mathrm{mL}$ solution.

\section{RESULTS}

The antioxidant activity of extracts calculated using DPPH method is presented in Table 1. Best result was that of $S$. ebulus flower extract obtained by percolation method $\left(\mathrm{IC}_{50}=9.5 \pm 0.9\right.$ $\mu \mathrm{g} / \mathrm{mL}$ ). S. ebulus flower extract (prepared using Soxhlet extractor, $\left.\mathrm{IC}_{50}=9.8 \pm 0.4 \mu \mathrm{g} / \mathrm{mL}\right)$, 0 . orientalis aerial part extract (prepared using ultra sonication, $\left(\mathrm{IC}_{50}=17.9 \pm 0.8 \mu \mathrm{g} / \mathrm{mL}\right), \quad A$. julibrissin leaf extract (prepared using ultra sonication, $\mathrm{IC}_{50}=21.6 \pm 0.6 \mu \mathrm{g} / \mathrm{mL}^{-1}$ ) and $S$. nigra leaf extract (prepared using ultra sonication, $\mathrm{IC}_{50}=21.6 \pm 0.8 \mu \mathrm{g} / \mathrm{mL}$ ) showed satisfactory degrees of antioxidant activity. These extracts all had a good antioxidant activity compared to the positive controls, vitamin $\mathrm{C}\left(\mathrm{IC}_{50}\right.$ $=3.7 \pm 0.1 \mu \mathrm{g} / \mathrm{mL})$ and $\mathrm{BHA}\left(\mathrm{IC}_{50}=29.3 \pm 5.9\right.$ $\mu \mathrm{g} / \mathrm{mL})$.

Table 1: Sun protection factor, total phenol contents, total and flavonoid contents and antioxidant activities of 42 tested extracts

\begin{tabular}{|c|c|c|c|c|c|c|c|}
\hline Plant name & $\begin{array}{l}\text { Extraction } \\
\text { method }\end{array}$ & $\begin{array}{l}\text { Part } \\
\text { used }\end{array}$ & $\begin{array}{l}\text { Extraction } \\
\text { yield (\%) }\end{array}$ & $\begin{array}{l}\text { Phenol conte } \\
\text { (GAE /g of } \\
\text { extract) }\end{array}$ & $\begin{array}{l}\text { sFlavonoids contents } \\
\text { (QE /g of extract) }\end{array}$ & $\begin{array}{l}\text { Antioxidant } \\
\text { activity } \\
\left(\mathrm{IC}_{50}\right) \\
\end{array}$ & $\begin{array}{l}\text { SPF } \\
\left(\text { at } 2 \mathrm{mg} \mathrm{ml}^{-1} \text { ) }\right.\end{array}$ \\
\hline \multirow[t]{6}{*}{ C. melo } & Ultrasonic & Leaf & 13.4 & $72.41 \pm 1.5$ & $19.47 \pm 1.1$ & $582.7 \pm 12.7$ & $0.841 \pm 0.02$ \\
\hline & Ultrasonic & Fruit & 20.5 & $88.62 \pm 3.7$ & $16.96 \pm 0.4$ & $780.1 \pm 19.6$ & $0.169 \pm 0.01$ \\
\hline & Percolation & Leaf & 15.6 & $71.20 \pm 2.5$ & $18.69 \pm 0.9$ & $115.0 \pm 3.7$ & $0.689 \pm 0.02$ \\
\hline & Percolation & Fruit & 21.9 & $77.57 \pm 1.3$ & $13.38 \pm 1.2$ & $975.6 \pm 31.5$ & $0.299 \pm 0.01$ \\
\hline & Soxhlet & Leaf & 16.6 & $111.77 \pm 3.4$ & $59.48 \pm 2.9$ & $445.3 \pm 10.3$ & $0.205 \pm 0.01$ \\
\hline & Soxhlet & Fruit & 30.8 & $80.92 \pm 2.1$ & $78.88 \pm 3.2$ & $643.8 \pm 22.8$ & $0.144 \pm 0.00$ \\
\hline \multirow[t]{9}{*}{ S. nigra } & Ultrasonic & Leaf & 18.5 & $185.24 \pm 6.3$ & $58.56 \pm 2.4$ & $21.6 \pm 0.8$ & $0.245 \pm 0.01$ \\
\hline & Ultrasonic & Fruit & 14.5 & $71.98 \pm 2.1$ & $42.53 \pm 1.3$ & $548.4 \pm 15.5$ & $0.446 \pm 0.02$ \\
\hline & Ultrasonic & Bark & 3.2 & $100.86 \pm 3.7$ & $38.63 \pm 0.8$ & $193.1 \pm 8.7$ & $0.311 \pm 0.01$ \\
\hline & Percolation & Leaf & 8.5 & $132.34 \pm 3.4$ & $109.48 \pm 7.1$ & $1472.4 \pm 32.1$ & $0.245 \pm 0.01$ \\
\hline & Percolation & Fruit & 17.5 & $99.32 \pm 2.9$ & $19.62 \pm 1.5$ & $1227.3 \pm 39.7$ & $0.159 \pm 0.00$ \\
\hline & Percolation & Bark & 2.4 & $168.96 \pm 4.7$ & $81.43 \pm 2.7$ & $831.4 \pm 24.1$ & $0.365 \pm 0.02$ \\
\hline & Soxhlet & Leaf & 11.4 & $115.86 \pm 5.1$ & $101.94 \pm 2.9$ & $769.7 \pm 19.8$ & $0.285 \pm 0.01$ \\
\hline & Soxhlet & Fruit & 3.2 & $158.62 \pm 4.6$ & $45.60 \pm 1.1$ & $844.6 \pm 18.9$ & $0.086 \pm 0.00$ \\
\hline & Soxhlet & Bark & 4.2 & $159.13 \pm 6.3$ & $33.06 \pm 0.7$ & $845.9 \pm 21.1$ & $0.333 \pm 0.01$ \\
\hline \multirow[t]{6}{*}{ V. faba } & Ultrasonic & Bean & 6.6 & $54.16 \pm 2.5$ & $27.59 \pm 1.1$ & $918.7 \pm 34.5$ & $0.067 \pm 0.00$ \\
\hline & Ultrasonic & Hull & 9.12 & $103.38 \pm 3.3$ & $33.62 \pm 1.3$ & $56.9 \pm 2.5$ & $0.083 \pm 0.00$ \\
\hline & Percolation & Bean & 14.6 & $69.16 \pm 2.8$ & $22.59 \pm 0.9$ & $1143.7 \pm 40.2$ & $0.057 \pm 0.00$ \\
\hline & Percolation & Hull & 32.3 & $78.62 \pm 3.6$ & $62.75 \pm 1.4$ & $85.8 \pm 3.8$ & $0.174 \pm 0.01$ \\
\hline & Soxhlet & Bean & 12.4 & $56.57 \pm 1.4$ & $28.45 \pm 1.1$ & $697.0 \pm 23.3$ & $0.104 \pm 0.01$ \\
\hline & Soxhlet & Hull & 39.5 & $110.25 \pm 6.1$ & $60.52 \pm 2.5$ & $87.3 \pm 3.4$ & $0.093 \pm 0.00$ \\
\hline \multirow[t]{3}{*}{ A. absinthium } & Ultrasonic & Aerial & 16.5 & $171.77 \pm 5.8$ & $136.25 \pm 5.5$ & $364.1 \pm 14.7$ & $0.606 \pm 0.02$ \\
\hline & Percolation & Aerial & 25.4 & $188.58 \pm 4.6$ & $113.00 \pm 5.3$ & $345.1 \pm 16.4$ & $0.717 \pm 0.02$ \\
\hline & Soxhlet & Aerial & 28.4 & $220.69 \pm 6.3$ & $136.45 \pm 4.9$ & $191.6 \pm 7.2$ & $0.346 \pm 0.01$ \\
\hline \multirow[t]{6}{*}{ A. julibrissin } & Ultrasonic & Leaf & 15.4 & $565.52 \pm 22.8$ & $139.66 \pm 6.2$ & $21.6 \pm 0.6$ & $0.247 \pm 0.01$ \\
\hline & Ultrasonic & Flower & 12.7 & $340.35 \pm 14.6$ & $136.66 \pm 5.7$ & $54.9 \pm 2.1$ & $0.436 \pm 0.02$ \\
\hline & Percolation & Leaf & 26.7 & $213.15 \pm 8.7$ & $88.00 \pm 2.9$ & $106.2 \pm 3.4$ & $0.401 \pm 0.02$ \\
\hline & Percolation & Flower & 30.7 & $132.54 \pm 5.6$ & $98.95 \pm 3.2$ & $208.4 \pm 4.9$ & $0.415 \pm 0.01$ \\
\hline & Soxhlet & Leaf & 20.8 & $688.97 \pm 23.3$ & $121.19 \pm 5.4$ & $24.3 \pm 0.9$ & $0.262 \pm 0.00$ \\
\hline & Soxhlet & Flower & 28.1 & $321.38 \pm 13.2$ & $121.50 \pm 4.8$ & $61.1 \pm 1.4$ & $0.237 \pm 0.01$ \\
\hline \multirow[t]{3}{*}{ O. orientalis } & Ultrasonic & Aerial & 14.1 & $361.55 \pm 12.3$ & $46.81 \pm 1.7$ & $17.9 \pm 0.8$ & $0.634 \pm 0.02$ \\
\hline & Percolation & Aerial & 23.4 & $384.48 \pm 14.7$ & $60.56 \pm 2.4$ & $31.9 \pm 0.9$ & $0.399 \pm 0.01$ \\
\hline & Soxhlet & Aerial & 18.5 & $323.28 \pm 12.0$ & $62.42 \pm 2.3$ & $43.3 \pm 1.8$ & $0.479 \pm 0.01$ \\
\hline \multirow{3}{*}{ D. racemosa } & Ultrasonic & Leaf & 8.5 & $248.28 \pm 10.1$ & $136.25 \pm 3.4$ & $135.9 \pm 4.9$ & $0.283 \pm 0.00$ \\
\hline & Percolation & Leaf & 14.4 & $268.97 \pm 9.3$ & $146.60 \pm 5.5$ & $115.6 \pm 2.8$ & $0.395 \pm 0.01$ \\
\hline & Soxhlet & Leaf & 20.1 & $256.06 \pm 11.5$ & $131.17 \pm 4.0$ & $104.6 \pm 2.6$ & $0.236 \pm 0.01$ \\
\hline \multirow{3}{*}{ S. ebulus } & Ultrasonic & Flower & 12.0 & $81.33 \pm 3.2$ & $52.41 \pm 1.6$ & $617.3 \pm 22.8$ & $0.344 \pm 0.01$ \\
\hline & Percolation & Flower & 15.0 & $84.31 \pm 2.5$ & $49.93 \pm 1.1$ & $9.5 \pm 0.9$ & $0.589 \pm 0.03$ \\
\hline & Soxhlet & Flower & 33.4 & $75.69 \pm 1.8$ & $51.55 \pm 2.2$ & $9.8 \pm 0.4$ & $0.247 \pm 0.00$ \\
\hline \multirow[t]{3}{*}{ E. amoenum } & Ultrasonic & Petals & 22.3 & $75.83 \pm 2.8$ & $39.88 \pm 1.4$ & $151.9 \pm 3.6$ & $0.222 \pm 0.01$ \\
\hline & Percolation & Petals & 29.0 & $74.21 \pm 2.1$ & $42.64 \pm 1.6$ & $162.3 \pm 4.1$ & $0.124 \pm 0.00$ \\
\hline & Soxhlet & Petals & 31.0 & $84.25 \pm 3.4$ & $37.93 \pm 1.5$ & $99.6 \pm 4.5$ & $0.208 \pm 0.01$ \\
\hline
\end{tabular}

Values are expressed as mean $\pm S D$ of three determinations 
The values of total phenolics and flavonoids content in the extracts are shown in Table 1. The highest value of phenolic compounds was that $A$. julibrissin leaf extract prepared by soxhlet extractor ( $688.97 \pm 23.3 \mathrm{mg} \mathrm{GAE} / \mathrm{g}$ of extract). $A$. julibrissin leaf extract prepared using ultra sonication also had high content of phenolic compounds as well (565.52 $\pm 22.8 \mathrm{mg} \mathrm{GAE} / \mathrm{g}$ of extract). However, the highest flavonoids content (146.60 $\pm 5.5 \mathrm{mg} \mathrm{QE} / \mathrm{g}$ of extract) was that of $D$. racemosa leaf extract prepared by percolation method. A. julibrissin leaf extract (prepared by ultrasonication, $139.66 \pm 6.2 \mathrm{mg} \mathrm{QE} / \mathrm{g}$ of extract) had considerable quantity of flavonoid compounds as well. For the SPFs values of the extracts, the highest values was for Cucumis melo leaf extract (obtained by ultra sonication) and Artemisia absinthium shoots (methanolic extract) with SPF values of 0.841 and 0.717 , respectively.
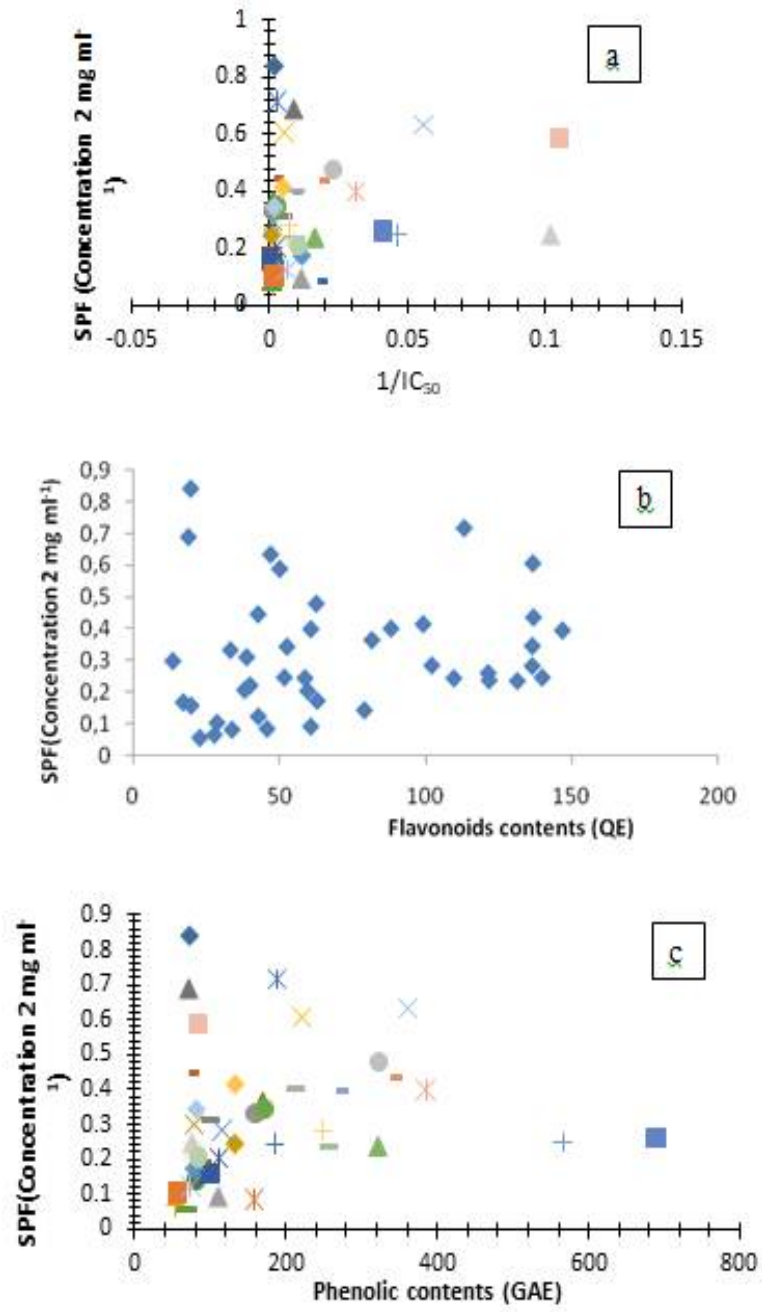

Figure 1: Correlation between SPF and antioxidant activity (a), flavonoid content (b) and phenolic content (c) in 42 tested extracts
The correlation between SPF with either phenolic $(r=0.469, p=0.003)$ and flavonoid $(r=0.355, p=$ 0.023 ) contents and antioxidant activity was significant. But no significant correlations existed between SPF and antioxidant activity $(r=0.242$, $p=0.132$ ) in the extracts (Figure 1).

\section{DISCUSSION}

In this research, 42 extracts from nine known medicinal plants were evaluated for their SPF using UV spectrophotometry. We found that $S$. ebulus flower extract (obtained by percolation), $S$. ebulus flower extract (obtained by soxhlet extractor), and $O$. orientalis shoot extract (obtained by ultra-sonication) had considerable antioxidant activity when compared with vitamin $\mathrm{C}$ and butylated hydroxyl anisole (BHA).

Antioxidant activity is important in UV protection [22]. It seems that the already reported photoprotective effect of $p$. umbellata is due to its antioxidant activity [23]. The flavonoids and polyphenols studied are good candidates for use in photoprotective products $[24,25]$. Phenolic compounds are believed to be capable of acting in redox-sensitive signaling cascades to inhibit DNA damage $[23,26]$. They may also be beneficial in preventing UV-induced oxygen free radical generation and lipid peroxidation.

We found that $A$. julibrissin and $D$. racemosa leaf extracts have high quantities of phenolic compounds. The highest values were obtained by ultrasonic extract of $C$. melo leaf and percolation extract of $A$. absinthium aerial parts with SPF values of 0.841 and SPF $=0.717$ respectively. High SPF values have been reported from leaf extract of $D$. moldavica and flowering tops of $V$. tricolor (24.79 and 25.69, respectively) [21] often considered to be due to high phenolic contents [20]. The protective power identified in this study is vital as UV is highly genotoxic agent whose deleterious effects on human skin at DNA level has been widely accepted [22]. To prevent UV-mediated DNA damage, sun protection factors are of highly interests. Although UV radiation has some benefits, e.g., for the biosynthesis of vitamin $D$, its negative impact on human health is much more. Skin cancer is one of the serious results.

\section{CONCLUSION}

There is a relatively significant correlation between SPF and both phenolic and flavonoid contents but not antioxidant activity. The application of ultrasonically assisted extract may be useful in achieving high SPF values in some plants. 


\section{DECLARATIONS}

\section{Acknowledgement}

This study was supported by a research grant (No. 91-242) registered in Mazandaran University of Medical Sciences (Sari, Iran).

\section{Conflict of interest}

No conflict of interest is associated with this work.

\section{Contribution of authors}

We declare that this work was done by the authors named in this article and all liabilities pertaining to claims relating to the content of this article will be borne by the authors.

\section{Open Access}

This is an Open Access article that uses a funding model which does not charge readers or their institutions for access and distributed under the terms of the Creative Commons Attribution License (http://creativecommons.org/licenses/by/ 4.0) and the Budapest Open Access Initiative (http://www.budapestopenaccessinitiative.org/rea d), which permit unrestricted use, distribution, and reproduction in any medium, provided the original work is properly credited.

\section{REFERENCES}

1. Dutra EA, Oliveira DA, Kedor-Hackmann ERM, Santoro MI. Determination of sun protection factor (SPF) of sunscreens by ultraviolet spectrophotometry. Braz J Pharm Sci 2004; 40(3): 381-385.

2. Melnikova VO, Ananthaswamy HN. Cellular and molecular events leading to the development of skin cancer. Mutat Res 2005; 571(1-2): 91-106.

3. Vainio H, Bianchini F. Cancer-preventive effects of sunscreens are uncertain. Scand J Work Environ Health 2000; 26: 529-531.

4. Kale Sh, Wane AS, Ansari A, Ghoge $P$, Waje $A$. Formulation and in vitro determination of sun protection factor of Ocimum basilicum Linn. leaf oils sunscreen cream. Int J Pharm Pharm Sci 2010; 2(Suppl 4): 147-149.

5. Rancan F, Rosan S, Boehm K, Fernandez E, Hidalgo ME, Quihot W, Rubio C, Boehm F, Piazena H, Oltmanns $U$. Protection against UVB irradiation by natural filters extracted from lichens. J Photochem Photobiol 2002; 68: 133-139.
6. Liu MC, Lin CT, Shau MD, Chen ZS, Chen MT. Studies on natural ultraviolet absorbers. J Food Drug Anal 1996; 4: 243-248.

7. Bonina F, Lanza M, Montenegro L, Puglisi C, Tomaino A, Trombetta $D$. Flavonoids as potential protective agents against photo-oxidative skin damage. Int J Pharm 1996; 145: 87-91.

8. Urbach F. The historical aspects of sunscreens. J Photochem Photobiol 2001; 64: 99-104.

9. Wang ZY, Agarwal R, Bickers DR, Mukhtar H. Protection against ultraviolet $B$ radiation-induced photocarcinogenesis in hairless mice by green tea polyphenols. Carcinogenesis 1991; 12: 1527-1532.

10. Patil RB, Kale Sh, Badiyani DM, Yadav AV. Determination of in-vitro sun protection factor (SPF) of Murraya koenigii L. (Rutaceae) essential oil formulation. Ind J Pharm Edu Res 2010; 44(4): 375-379.

11. Mahmoudi M, Ebrahimzadeh MA, Ansaroudi F, Nabavi SF, Nabavi SM. Antidepressant and antioxidant activities of Artemisia absinthium L. at flowering stage. Afr J Biotechnol 2009; 8(24): 7170-7175.

12. Ebrahimzadeh MA, Ehsanifar S, Eslami B. Sambucus ebulus elburensis fruits: $A$ good source for antioxidants. Pharmacogn Mag 2009; 4(19): 213-218.

13. Forouzani M, Askari M, Ebrahimzadeh MA. Evaluation of three methods for the extraction of antioxidants from Cucumis melo $L$. fruit and leaves. Int J Forest Soil Erosion 2013; 3(3): 95-99

14. Ebrahimzadeh $M A$, Enayatifard R, Saeedi $M$, Khalili $M$, Ghaffarloo M, Yazdani Charati J. Correlation between sun protection factor and antioxidant activity, phenol and flavonoid contents of some medicinal plants. Iran $\mathrm{J}$ Pharm Res 2014; 13 (3): 1041-1047.

15. Rabiei Kh, Bekhradnia S, Nabavi SM, Nabavi SF, Ebrahimzadeh MA. Antioxidant activity of polyphenol and ultrasonic extracts from fruits of Crataegus pentagyna subsp. elburensis. Nat Pro Res 2012; 26(24): 2353-2357.

16. Chang C, Yang M, Wen H, Chern J. Estimation of total flavonoid content in propolis by two complementary colorimetric methods. J Food Drug Anal 2002; 10: 178182.

17. Ebrahimzadeh MA, Nabavi SM, Nabavi SF, Eslami B. Free radical scavenging ability of methanolic extract of Hyoscyamus squarrosus leaves. Pharmacologyonline 2009; 2: 796-802.

18. Diffey BL, Robson J. A new substrate to measure sunscreen protection factors throughout the ultraviolet spectrum.J Soc Cosmetic Chem 1989; 40: 127-133.

19. Gharavi SM, Tavakoli N, Pardakhti A, Baghaeizadeh N. Determination of sun protection factor of sunscreens by two different in vitro methods. J Res Med Sci 1999; 2: 53-54.

20. Khazaeli $P$, Mehrabani M. Screening of sun protective activity of the ethyl acetate extracts of some medicinal plants. Iran J Pharm Res 2008; 7(1): 5-9.21. Bajpai M, Parade A, Tiwari SK, Prashad D. Phenolic content and 
antioxidant activity of some food and medicinal plants. Int J Food Sci Nut 2005; 4: 287-291.

21. Kittiwannachot $P$, Borisut $P$, Wanasawas $P$, Ponpanich $L$, Rattanasuk O, Chulasiri M. Antimutagenic potentials of hydroalcoholic herbal extracts towards UV- induced mutation. Thai J Toxicol 2008; 23(1): 27-34.

22. Da Silva $V V$, Ropke $C D$, de Almeida RL, Miranda $D V$, Kera CZ, Rivelli DP, Sawada TC, Barros SB. Chemical stability and SPF determination of Pothomorphe umbellata extract gel and photostability of 4nerolidylcathecol. Int J Pharm 2005; 303:125-131.
23. Svobodova A, Psotova J, Walterova D. Natural phenolic in the prevention of UV-induced skin damage, a review. Biomedical Papers 2003; 147: 137-145.

24. Choquenet B, Couteau C, Paparis E, Coiffard LJM. Flavonoids and polyphenols, molecular families with sunscreen potential: Determining effectiveness with an invitro method. Nat Prod Commun 2009; 4(2): 227-230.

25. Grover IS, Bala, S. Studies on antimutagenic effects of guava (Psidium guajava) in Salmonella typhimurium. Mutat Res 1993; 300: 1-3. 